\title{
MOBILIDADE DO AMETRYN EM LATOSSOLOS BRASILEIROS ${ }^{1}$
}

\author{
Mobility of Ametryn in Brazilian Latosols \\ SILVA, L.O.C. ${ }^{2}$, SILVA, A.A. ${ }^{3}$, QUEIROZ, MARIA E.L.R. ${ }^{4}$, LIMA, C.F. ${ }^{4}$, SILVA, L.L. ${ }^{5}$ e \\ D'ANTONINO, L. ${ }^{6}$
}

\begin{abstract}
RESUMO - O conhecimento dos fatores que influenciam a lixiviação dos herbicidas no solo possibilita o uso seguro do produto do ponto de vista ambiental, além de ser fundamental para que se façam recomendações tecnicamente corretas. Objetivou-se com este trabalho avaliar a lixiviação do ametryn em quatro solos brasileiros, com diferentes características físico-químicas, e comparar o método cromatográfico com o biológico em estudos de mobilidade desse herbicida. Os substratos avaliados foram: Latossolo Vermelho-Amarelo (LVA) pH 5,40 e pH 6,11, Latossolo Vermelho-Amarelo húmico (LVAh) pH 4,8 e pH 6,24, Latossolo Vermelho (LV) $\mathrm{pH} 5,00$ e $\mathrm{pH}$ 6,06 e Latossolo Amarelo (LA) pH 6,30 e 10 profundidades na coluna (0-5, $5-10,10-15,15-20,20-25,25-30,30-35,35-40,40-45$ e $45-50 \mathrm{~cm}$ ), mais uma testemunha de cada substrato sem aplicação do herbicida, com quatro repetições. Os substratos foram colocados em colunas devidamente preparadas para estudos de mobilidade. A espécie Cucumis sativus foi utilizada como bioindicadora da presença do ametryn. Concluiu-se que os teores de matéria orgânica e $\mathrm{pH}$ dos solos avaliados foram as características que mais interferiram na mobilidade do ametryn e que o ensaio biológico se mostrou eficiente como indicador da lixiviação desse herbicida nas colunas. Comprovou-se que o método biológico por bioensaios pode ser utilizado como método preliminar ou complementar ao método instrumental, visando à confirmação de resultados e, ou, redução de custos e tempo das análises.
\end{abstract}

Palavras-chave: herbicida, impacto ambiental, características do solo, bioensaio, cromatografia líquida.

ABSTRACT - The knowledge of the factors that influence herbicide leaching in the soil enables the safe use of the product in the environment, besides being fundamental in the formulation of technically correct recommendations. The objectives of this study were to evaluate ametryn leaching in four Brazilian soils with different physicochemical characteristics, and to compare the chromatographic and biological methods in studies on this herbicide's mobility. The substrates used were: Red-Yellow Latosol (LVA) pH 5.40 and pH 6.11, Red-Yellow humic Latosol (LVAh) pH 4.8 and pH 6.24, Red Latosol (LV) and pH 5.00 pH 6.06 and Yellow Latosol (LA) pH 6.30 and 10 depths in the column (0-5, 5-10, 10-15, 15-20, 20-25, 25-30, 30-35, $35-40,40-45$ and 45-50 cm) and a control without herbicide application on each substrate, with four replications. The substrates were placed in columns properly prepared for mobility studies. The species Cucumis sativus was used as a bio-indicator of the presence of ametryn. It was concluded that the organic matter levels and soil pH evaluated were the characteristics that most interfered with ametryn's mobility and that the biological assay proved to be effective as an indicator of this herbicide's leaching in the columns. Therefore, the method for biological assays can be used as a preliminary method or as a complement to the instrumental method to confirm results and/or the reduction of costs and analysis time.

Keywords: herbicide, environmental impact, soil characteristics, bioassay, liquid chromatography.

Recebido para publicação em 29.7.2011 e aprovado em 22.2.2012.

2 D.Sc., Professora, Núcleo de Química do Instituto Federal de Educação, Ciência e Tecnologia do Sudeste de Minas - Campus Barbacena - IFSUDESTEMG; ${ }^{3}$ D.Sc., Professor Associado, Dep. de Fitotecnia, Universidade Federal de Viçosa - DFT/UFV; ${ }^{4}$ D.Sc., Professor Associado, Departamento de Química - DEQ/UFV; ${ }^{5}$ Eng ${ }^{\circ}-$ Agr $^{\circ}$., M.Sc., DFT/UFV; ${ }^{6}$ Eng ${ }^{-}-$Agr ${ }^{\circ}$., D.Sc., DFT/UFV. 


\section{INTRODUÇÃO}

Com o aumento do uso de herbicidas, tornaram-se mais frequentes os casos de contaminação do solo e da água por alguns desses produtos, causando sérios problemas ambientais (Coleman et al., 2002; Celis et al., 2005). Para preveni-los, é necessário conhecimento das interações dos diferentes herbicidas com as características de cada solo que influenciarão a sorção, a meia-vida e a lixiviação dessas moléculas.

A lixiviação desses compostos é um processo bastante complexo e sofre influência, por exemplo, de fatores como clima, propriedades do solo e características físico-químicas das moléculas dos herbicidas (Kordel \& Klein, 2006). A sorção de herbicidas em solos interfere na quantidade de produto presente na solução do solo, bem como na eficácia do controle das plantas daninhas e na permanência de resíduos desses compostos no ambiente (Andrade, 2008), e, consequentemente, está diretamente relacionada com a movimentação desses xenobióticos no perfil de solos.

Há grande variedade de modelos para avaliar o destino ambiental de substâncias e, em particular, sua transferência para águas superficiais e subterrâneas após serem aplicados em áreas agrícolas (Dubus et al., 2003). Um método simples e que requer pouco investimento em equipamentos e recursos consiste no bioensaio, no qual espécies indicadoras são cultivadas em solo previamente contaminado. Há também métodos instrumentais, como os cromatográficos, mais sofisticados e de maior custo (Silva \& Silva, 2007).

Entre os herbicidas utilizados no Brasil, destaca-se o ametryn, que pertence à classe das triazinas e é utilizado em pré e pós-emergência no controle de mono e dicotiledôneas de plantas daninhas em diversas culturas (Jacomini et al., 2009). Devido ao grande uso do ametryn na cultura da cana-de-açúcar, esse herbicida tem sido aplicado, repetidas vezes, em diferentes solos sem o conhecimento básico de suas interações com estes. Isso tem levado ao uso incorreto do herbicida quanto às doses aplicadas, tendo como consequência a contaminação do solo e das águas superficiais em regiões canavieiras (Queiroz \& Lanças, 1997; Monquero et al., 2008; Jacomini et al., 2009).
Objetivou-se com este trabalho avaliar a lixiviação do ametryn em quatro latossolos brasileiros, com diferentes características físicoquímicas e valores de $\mathrm{pH}$ natural e corrigido, e comparar o método cromatográfico com o biológico em estudos de mobilidade desse herbicida.

\section{MATERIAL E MÉTODOS}

As amostras dos solos foram coletadas nas profundidades de 0 a $20 \mathrm{~cm}$, em diferentes áreas sem histórico de aplicação do ametryn, sendo: um Latossolo Amarelo (LA) do município de Sooretama, ES, em área de cafezal abandonado; em Latossolo Vermelho-Amarelo (LVA) do município de Viçosa, MG, em área de pastagem degradada; um Latossolo VermelhoAmarelo húmico (LVAh) do município de Viçosa, MG, em área de mata atlântica; e um Latossolo Vermelho (LV) do município de Três Marias-MG, em área de cultura de eucalipto.

As características químicas e físicas dos solos estudados estão apresentadas nas Tabelas 1 e 2, respectivamente. $\mathrm{O}$ pH dos solos foi corrigido para valores próximos de 6,0 condição comum em solos utilizados para práticas agrícolas - com base em curvas de neutralização geradas para os diferentes solos, exceto o solo LA. A partir dessa etapa, trabalhou-se com os solos nas seguintes condições: LVA pH 5,40; LVA pH 6,11; LVAh pH 4,80; LVAh pH 6,24; LV pH 5,00; LV pH 6,06; e LA pH 6,30.

Colunas de PVC foram utilizadas e preparadas de forma semelhante à de estudos realizados por Inoue et al. (2007), Andrade (2008) e Chopra et al. (2010). As colunas apresentavam $10 \mathrm{~cm}$ de diâmetro por $50 \mathrm{~cm}$ de comprimento, marcadas e seccionadas a cada $5 \mathrm{~cm}$. O experimento foi realizado em delineamento inteiramente casualizado, em esquema de parcelas subdivididas, com quatro repetições, composto por 70 tratamentos, que consistiram em sete solos e 10 profundidades (desenvolvimento das plantas indicadoras nos substratos das colunas nas profundidades de 0-5, 5-10, 10-15, 15-20, 20-25, 25-30, 30-35, 35-40, 40-45 e 45-50 cm). Em complementação, foi utilizada uma testemunha sem herbicida para cada solo.

Após o preparo das colunas e preenchimento com amostras dos solos, elas foram umedecidas e colocadas na posição vertical 
Tabela 1 - Resultados das análises químicas das amostras de Latossolo Vermelho-Amarelo (LVA), Latossolo Vermelho-Amarelo húmico (LVAh), Latossolo Vermelho (LV) e Latossolo Amarelo (LA)

\begin{tabular}{|c|c|c|c|c|c|c|c|c|c|c|c|c|c|}
\hline \multirow{2}{*}{ Solo } & $\mathrm{pH}$ & $\mathrm{P}$ & $\mathrm{K}$ & $\mathrm{Ca}$ & $\mathrm{Mg}$ & $\mathrm{Al}$ & $\mathrm{H}+\mathrm{Al}$ & SB & $(\mathrm{t})$ & $(\mathrm{T})$ & $\mathrm{V}$ & $\mathrm{m}$ & $\mathrm{MO}$ \\
\hline & $\left(\mathrm{H}_{2} \mathrm{O}\right)$ & \multicolumn{3}{|c|}{$\left(\mathrm{mg} \mathrm{dm}^{-3}\right)$} & \multicolumn{6}{|c|}{$\left(\mathrm{cmol}_{\mathrm{c}} \mathrm{dm}^{-3}\right)$} & \multicolumn{2}{|c|}{$(\%)$} & $\left(\right.$ dag kg $\left.{ }^{-1}\right)$ \\
\hline LVA & 5,4 & 3,5 & 50 & 0,8 & 0,3 & 0,8 & 8,91 & 1,38 & 2,18 & 10,29 & 13 & 37 & 3,7 \\
\hline LVAh & 4,8 & 2,0 & 46 & 0,6 & 0,7 & 1,4 & 10,73 & 1,42 & 2,82 & 12,15 & 12 & 50 & 4,3 \\
\hline LV & 5,0 & 0,8 & 14 & 0,2 & 0,0 & 0,4 & 3,30 & 0,24 & 0,64 & 3,54 & 7 & 63 & 0,8 \\
\hline LA & 6,3 & 9,6 & 110 & 2,9 & 1,0 & 0,0 & 1,32 & 4,18 & 4,18 & 5,50 & 76 & 0 & 2,2 \\
\hline
\end{tabular}

Fonte: Embrapa (1997).

Tabela 2 - Resultados das análises físicas das amostras de Latossolo Vermelho-Amarelo (LVA), Latossolo Vermelho-Amarelo húmico (LVAh), Latossolo Vermelho (LV) e Latossolo Amarelo (LA)

\begin{tabular}{|l|c|c|c|c|c|}
\hline \multirow{2}{*}{ Solo } & Areia grossa & Areia fina & Silte & Argila & \multirow{2}{*}{ Classe textural } \\
\cline { 2 - 5 } & \multicolumn{4}{|c|}{$\left(\mathrm{dag} \mathrm{kg}^{-1}\right)$} \\
\hline LVA & 15 & 12 & 4 & 69 & Muito Argiloso \\
\hline LVAh & 23 & 13 & 5 & 59 & Muito Argiloso \\
\hline LV & 36 & 36 & 1 & 27 & Franco-Argiloarenoso \\
\hline LA & 60 & 19 & 1 & 20 & Franco-Arenoso \\
\hline
\end{tabular}

Fonte: Embrapa (1997).

para drenagem do excesso de água. Posteriormente, pulverizou-se nos topos delas o ametryn, na dose de 4,0 $\mathrm{kg} \mathrm{ha}^{-1}$, sendo esta a dose máxima recomendada para o controle de plantas daninhas na cultura de cana-de-açúcar (Brasil, 2005). Doze horas após a aplicação do herbicida, fez-se a simulação de chuva de $60 \mathrm{~mm}$, com intensidade de precipitação de $0,5 \mathrm{~mm} \mathrm{~min}^{-1}$. Decorridas 72 horas, as colunas foram abertas longitudinalmente e colocadas na posição horizontal. Na linha central da abertura lateral das colunas, realizou-se a coleta das amostras, sendo estas retiradas na parte central de cada seção de $5 \mathrm{~cm}$ e secas ao ar, peneiradas em malha de 2,0 $\mathrm{mm}$, para posterior análise por cromatografia liquida de alta eficiência (CLAE). Em seguida, procedeu-se ao ensaio biológico, que consistiu em semear três sementes de pepino (Cucumis sativus) por segmento, como planta indicadora da presença do ametryn.

A umidade do solo nas colunas durante a realização do ensaio foi mantida por meio de irrigações diárias, mantendo-se o solo próximo à capacidade de campo. A avaliação do índice de intoxicação das plantas indicadoras foi feita aos 14 dias após a emergência (DAE), sendo atribuídas notas de 0 (ausência de intoxicação) a 100 (morte da planta).
A extração do herbicida das amostras do solo coletadas em cada segmento da coluna foi feita utilizando-se a técnica de extração sólidolíquido com partição em baixa temperatura (ESL-PBT). O procedimento foi realizado de acordo com a metodologia proposta por Vieira et al. (2007) e Goulart et al. (2008), com adaptações de tempo, pH e composição da solução extratora otimizadas por De Paula (2007) e Andrade (2008). Para confirmação dos resultados obtidos por esses autores, foram realizados testes de extração e, em seguida, a quantificação dos extratos por CLAE. O processo consistiu em medir uma massa de 2,00 g de solo seco, previamente homogeneizado e quarteado, em frascos de vidro de tampa rosqueável com 22,0 $\mathrm{mL}$ de capacidade; em seguida, adicionaram-se $12,0 \mathrm{~mL}$ da mistura extratora, composta por $4,0 \mathrm{~mL}$ de água, $6,5 \mathrm{~mL}$ de acetonitrila e $1,5 \mathrm{~mL}$ de acetato de etila. Os frascos foram submetidos à agitação vertical durante 30 minutos. Posteriormente, as amostras foram deixadas por \pm 12 horas em freezer à temperatura de aproximadamente $-20^{\circ} \mathrm{C}$. Após esse período, fez-se a filtração comum da fração não congelada, que consiste no extrato orgânico e herbicida, para balão volumétrico de 10,0 mL. As frações que continham solo e água congelada foram descartadas. Após atingirem a 
temperatura ambiente, as soluções filtradas foram transferidas para um balão de fundo redondo com 10,0 $\mathrm{mL}$ de capacidade, para evaporação dos solventes em evaporador rotatório, à temperatura de $50 \pm 1{ }^{\circ} \mathrm{C}$. Após a evaporação, o balão de fundo redondo foi cuidadosamente lavado com três alíquotas de $0,50 \mathrm{~mL}$ de acetonitrila e o extrato final novamente filtrado em membrana de 0,45 $\mu \mathrm{m}$ e armazenado em vials de $1,5 \mathrm{~mL}$ de capacidade, para posterior análise por CLAE.

A determinação do ametryn foi feita utilizando-se um sistema de cromatografia líquida de alta eficiência, modelo Shimadzu LC 20AT, com detector UV-Vis (Shimadzu SPD 20A), coluna $\mathrm{C}_{18}$ de aço inox (Shimadzu VP- ODS Shim-pack $150 \mathrm{~mm}$ x 4,6 mm d.i.). A soluçãoestoque do herbicida foi preparada a partir do padrão com 98,3\% de pureza, na concentração de $1.000 \mu \mathrm{g} \mathrm{mL}^{-1}$ em acetonitrila; as soluções de trabalho foram preparadas a partir desta.
As condições cromatográficas para a análise foram: fase móvel: água e acetonitrila na proporção de 70:30 (v/v), respectivamente, acidificada com $0,02 \%$ de ácido fosfórico; fluxo: 1,0 mL min-1; volume de injeção: $20 \mu \mathrm{L}$; temperatura da coluna: $30{ }^{\circ} \mathrm{C}$; comprimento de onda: $245 \mathrm{~nm}$; e tempo de retenção de aproximadamente 5,5 minutos. As análises foram realizadas em triplicata.

A quantificação foi feita pela comparação das áreas obtidas nos cromatogramas pelo método de calibração externa. Os dados obtidos foram submetidos à análise de regressão, sendo a escolha dos modelos baseada no fenômeno biológico e os coeficientes das equações testados pelo teste t a $5 \%$ de significância.

\section{RESULTADOS E DISCUSSÃO}

Na Figura 1, observam-se as porcentagens de intoxicação das plantas indicadoras obtidas
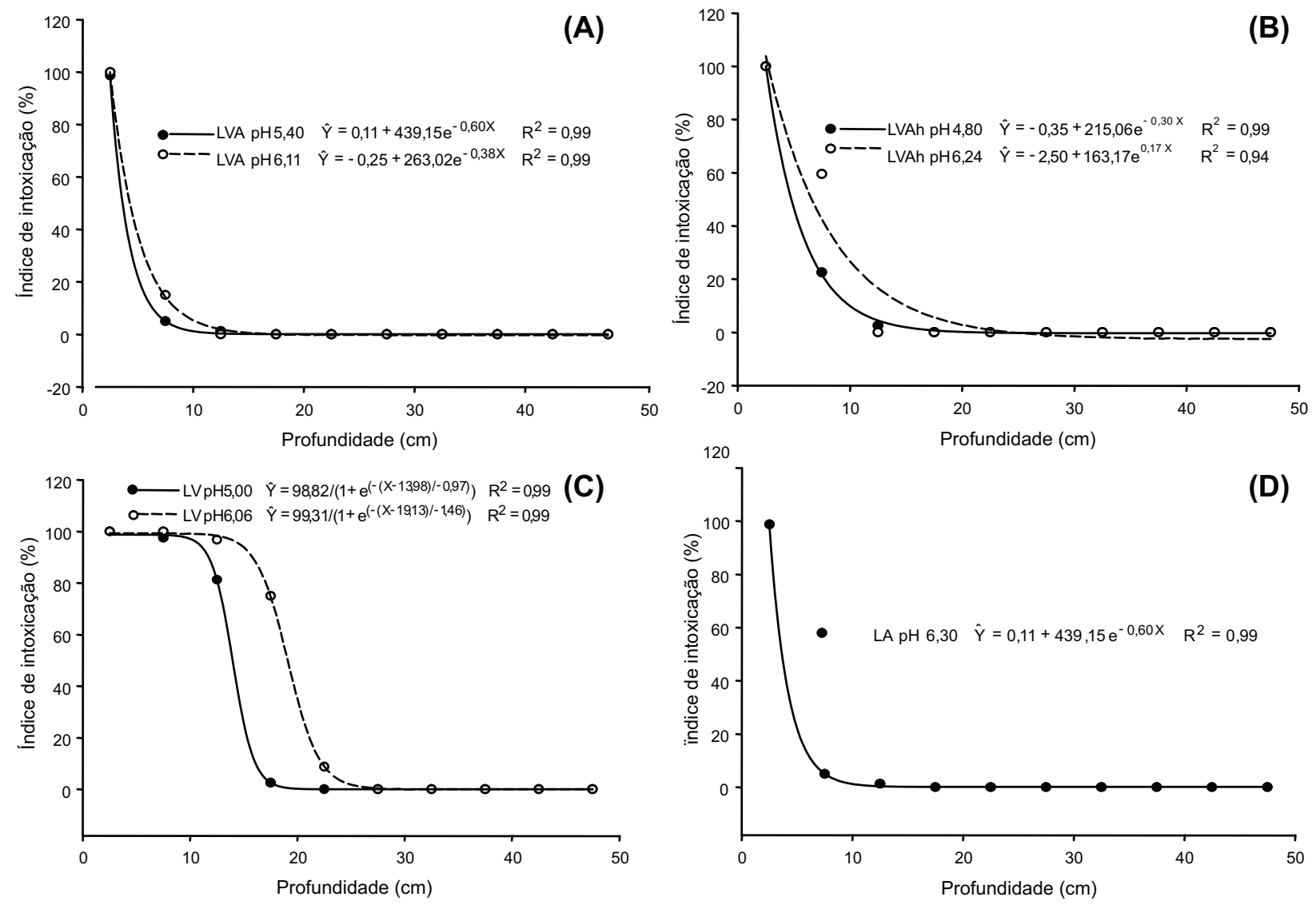

Figura 1 - Intoxicação de plantas de pepino em diferentes profundidades nas colunas, após aplicação de ametryn e simulação de chuva de $60 \mathrm{~mm}$, cultivadas em (A) Latossolo Vermelho-Amarelo (LVA), (B) Latossolo Vermelho-Amarelo húmico (LVAh), (C) Latossolo Vermelho (LV) e (D) Latossolo Amarelo (LA) com diferentes valores de $\mathrm{pH}$. 
por avaliação visual. Verifica-se que o ametryn causou a morte da planta indicadora na camada de 0 a $5 \mathrm{~cm}$ de profundidade em todos os solos. $\mathrm{Na}$ segunda profundidade (5 a $10 \mathrm{~cm}$ ) ocorreu a morte das plantas nos solos LV pH 5,00, LV pH 6,06 e LA pH 6,30; sintomas menos intensos foram observados nos demais segmentos. Na terceira profundidade, observou-se a morte e a intoxicação intensa nas plantas indicadoras nos solos LV pH 5,00 e LV pH 6,06, respectivamente. Na camada de 20 a $25 \mathrm{~cm}$, foi observada baixa porcentagem de intoxicação somente no LV pH 6,06.

Nos demais segmentos não foram observados danos causados pelo herbicida nas plantas de pepino, conforme ilustrado na Figura 2.
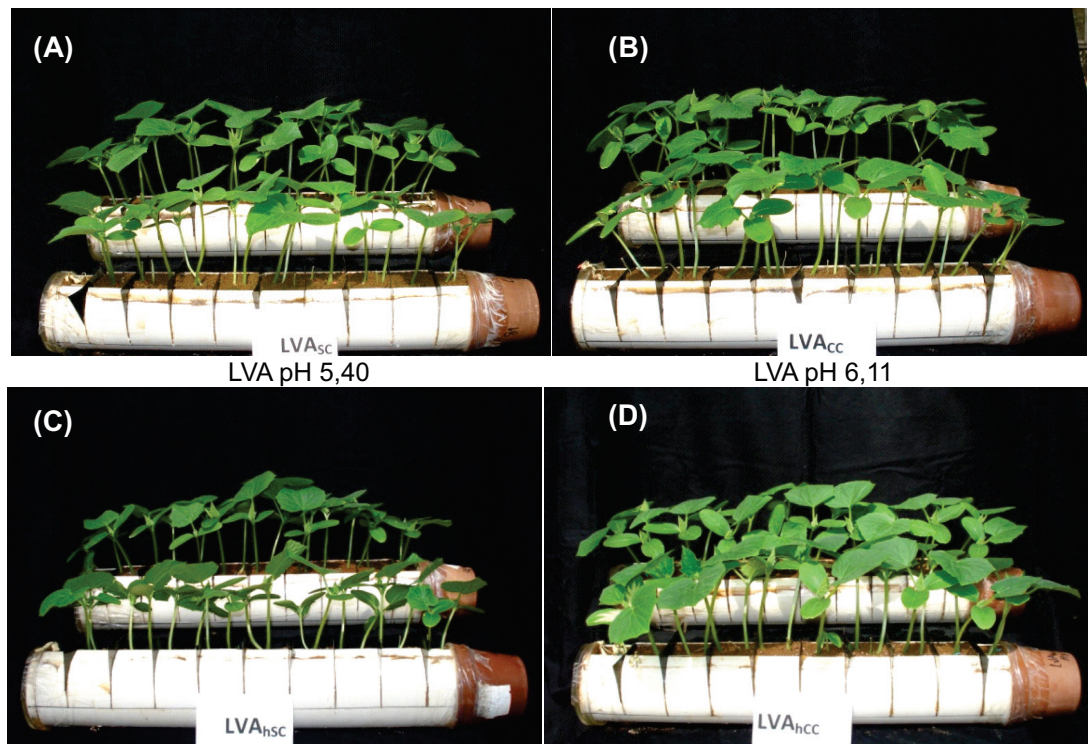

LVAh pH 4,8

LVAh $\mathrm{pH} 6,24$
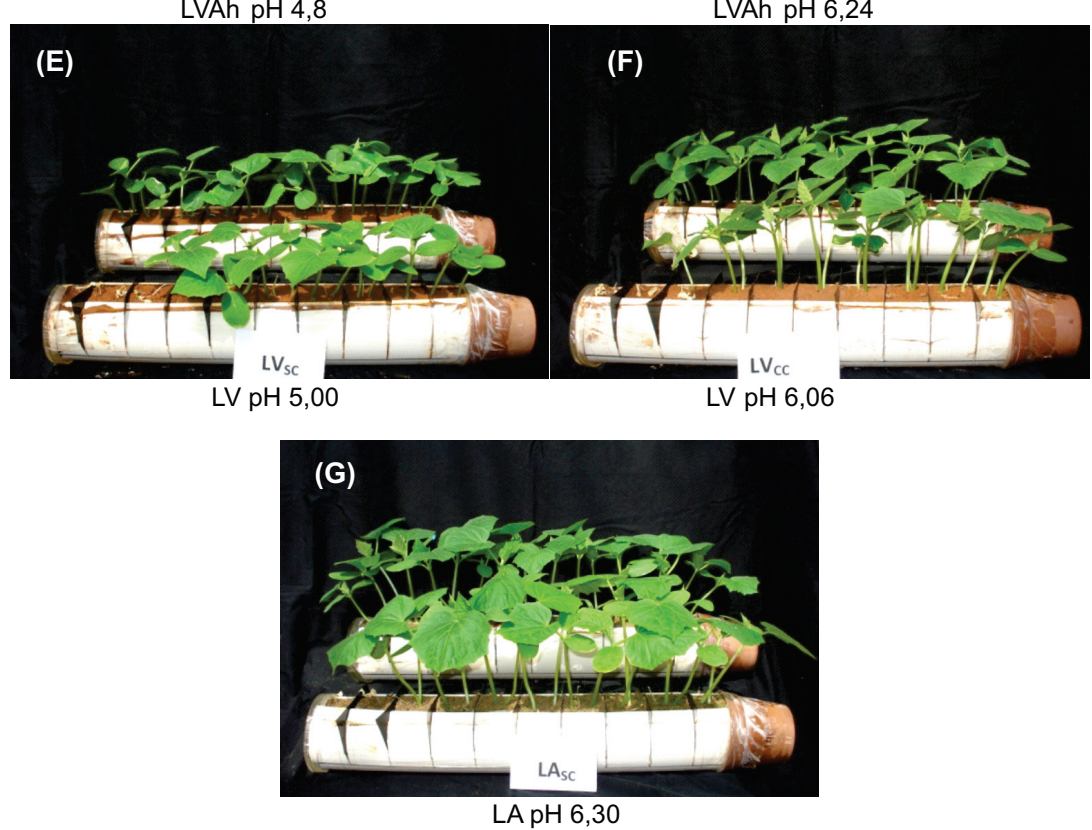

Figura 2 - Sintomas de intoxicação em plantas de pepino cultivadas em solos, tratados com ametryn, em função das profundidades das colunas e simulação de chuva de $60 \mathrm{~mm}$. (A) Latossolo Vermelho-Amarelo (LVA) pH 5,40; (B) Latossolo Vermelho-Amarelo (LVA) pH 6,11; (C) Latossolo Vermelho-Amarelo húmico (LVAh) pH 4,8; (D) Latossolo Vermelho-Amarelo húmico (LVAh) pH 6,24; (E) Latossolo Vermelho (LV) pH 5,00; (F) Latossolo Vermelho (LV) pH 6,06; e (G) Latossolo Amarelo (LA) $\mathrm{pH} 6,30$. 
A maior lixiviação do ametryn no solo LV pH 6,06 pode ser atribuída ao seu menor teor de matéria orgânica e ao fato de que a correção prévia do $\mathrm{pH}$ do solo favoreceu a diminuição da sorção do ametryn (Andrade, 2008). Menor intensidade de sintomas visuais foi observada nas plantas cultivadas no LVA, sendo este o solo que apresentou menor mobilidade do ametryn. Esse solo possui o maior teor de argila e o segundo maior valor de capacidade de troca cationnica e teor de matéria orgânica. O solo com maior capacidade de troca catiônica e teor de matéria orgânica e segundo maior teor de argila - o LVAh - apresentou a segunda menor mobilidade do ametryn (Tabelas 1 e 2). A fração húmica da matéria orgânica, em geral, apresenta maior relação com a sorção de herbicidas pelo solo. Contudo, há especificidades entre os componentes da fração humificada (Procópio et al., 2002). Dessa forma, a grande complexidade e variabilidade da matéria orgânica pode ter interferido na mobilidade do ametryn no LVAh, para o qual se esperava menor mobilidade do produto, além de outros fatores que podem agir sobre os fenômenos adsortivos, como as características mineralógicas (Monquero et al., 2010).

Comparando as concentrações do ametryn quantificadas nos diferentes solos com valores de $\mathrm{pH}$ próximos (Figura 3), observa-se relação inversa entre a mobilidade e os teores de matéria orgânica e argila. Em solos com maior teor de matéria orgânica o ametryn se movimentou menos nas colunas, evidenciando a maior sorção do herbicida às matrizes LVA e LVAh. Em trabalhos com o ametryn temse evidenciado a importância da matéria orgânica em sua sorção no solo, a qual apresenta grande influência nas propriedades fisico-químicas dos solos brasileiros (Andrade, 2008; Monquero et al., 2008). Segundo Rossi (2005), esse é um fator importante, pois, quanto mais alto o teor de matéria orgânica, maior será a sorção do herbicida e, com isso, menor a lixiviação.

Ao se compararem os solos com e sem correção de $\mathrm{pH}$, verifica-se que o aumento do $\mathrm{pH}$ favoreceu a lixiviação do produto. Herbicidas bases fracas, como o ametryn (pKa 4,1), podem atrair íons hidrogênio da solução do solo em condições de $\mathrm{pH}<\mathrm{pKa}$, passando a apresentar carga líquida positiva (Ferri et al., 2000). Solos com valores de $\mathrm{pH}$ próximos ao $\mathrm{pKa}$ do ametryn e maiores teores de matéria orgânica tendem à maior sorção e, consequentemente, menor lixiviação do herbicida no perfil do solo. O comportamento dependente da relação entre $\mathrm{pH}$ e pKa do herbicida foi observado por outros autores em estudos com herbicidas pertencentes ao mesmo grupo que o ametryn (Archangelo et al., 2005; Andrade, 2008; De Paula, 2007).

Quanto aos resultados observados pela análise cromatográfica (Figura 3), verificaramse variações das concentrações do ametryn em diferentes profundidades das colunas, de acordo com o tipo do solo avaliado, observando-se maior lixiviação nos solos LV e LA. Esses resultados confirmam os obtidos com o ensaio biológico (Figura 1), ou seja, na maioria dos segmentos em que se observou alta intoxicação das plantas indicadoras foram detectadas concentrações do ametryn.

As maiores concentrações foram observadas nos intervalos onde ocorreu a morte das plantas indicadoras. O método biológico mostrou-se bastante sensível; para o Latossolo Vermelho, permitiu detectar a presença do herbicida em profundidades maiores do que as detectadas pela cromatografia. Esse fato comprova a alta sensibilidade do método biológico para detectar a presença desse herbicida no solo, sendo possivel a sua utilização em estudos preliminares de lixiviação do ametryn. Além disso, a associação do método instrumental ao biológico pode reduzir o custo do trabalho, diminuindo o número de análises químicas a serem realizadas.

De outra forma, a técnica de cromatografia líquida permite quantificar o teor do herbicida ao longo do perfil do solo, mostrando o deslocamento dele nos diferentes segmentos (Figura 3). Nas colunas com o LV, a maior concentração do ametryn foi observada no segundo segmento $(5-10 \mathrm{~cm})$ em relação ao primeiro $(0-5 \mathrm{~cm})$ (Figura 3). Esse fato evidencia a percolação do composto no perfil do solo, o que pode resultar na redução da eficácia no controle de plantas daninhas que germinam em menores profundidades, em razão da menor disponibilidade do herbicida.

Conclui-se que o processo de lixiviação foi influenciado pelos teores de matéria orgânica 

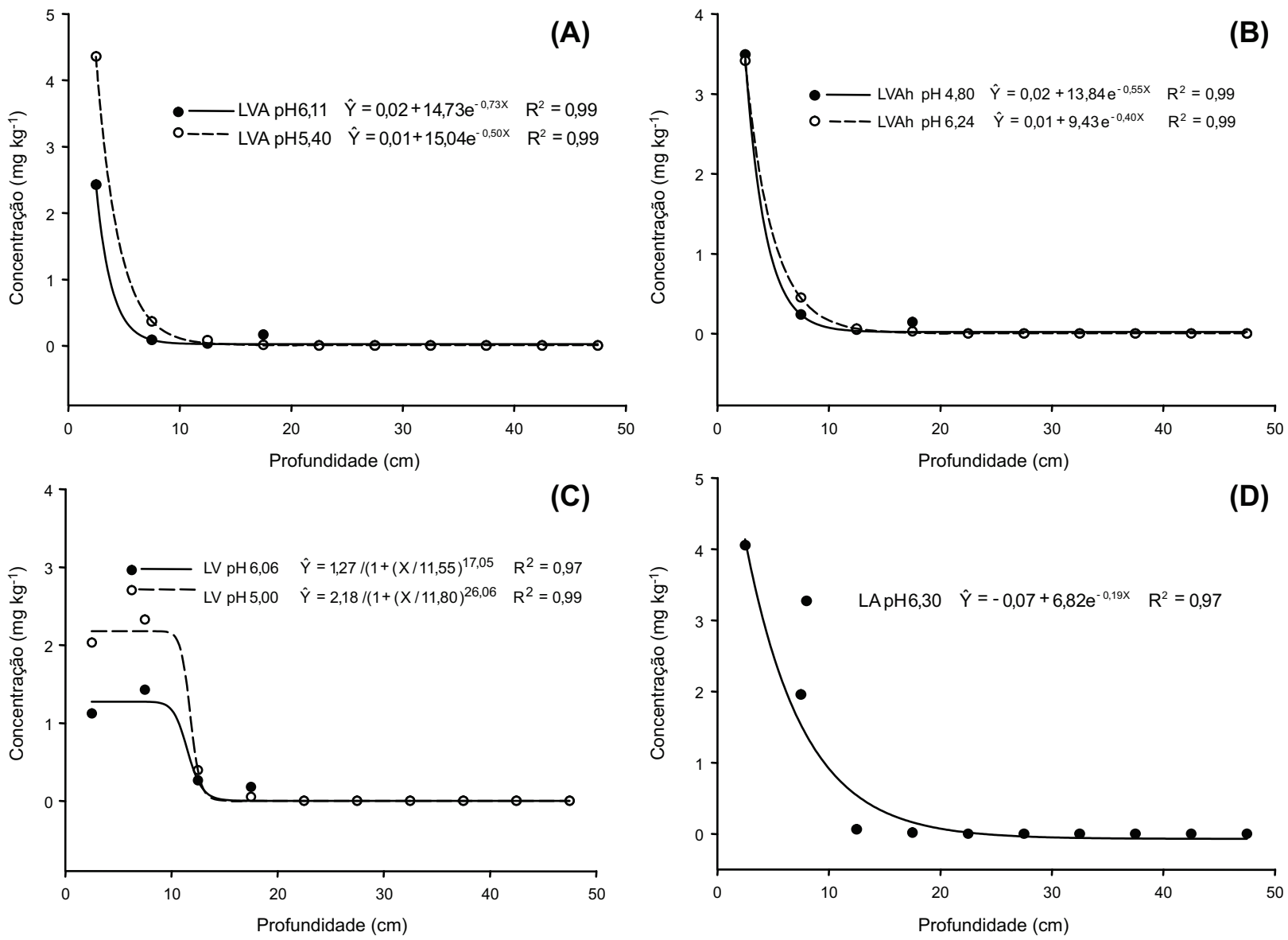

Figura 3 - Concentrações de ametryn, determinadas por cromatografia líquida, em diferentes profundidades das colunas, nos solos (A) Latossolo Vermelho-Amarelo (LVA), (B) Latossolo Vermelho-Amarelo húmico (LVAh), (C) Latossolo Vermelho (LV) e (D) Latossolo Amarelo (LA) com diferentes valores de $\mathrm{pH}$.

e pH dos solos e que o ensaio biológico foi eficiente na avaliação do potencial de lixiviação deste herbicida em colunas de solo; em solos com maiores teores de matéria orgânica e valores de $\mathrm{pH}$ mais próximos aos do $\mathrm{pKa}$ do herbicida foi observada menor movimentação do herbicida.

\section{LITERATURA CITADA}

ANDRADE, S. R. B. Avaliação da sorção, dessorção, meia vida e lixiviação do ametryn em argissolo vermelhoamarelo e latossolo vermelho-amarelo. 2008. 82 f. Tese (Doutorado em Fitotecnia) - Universidade Federal de Viçosa, Viçosa, MG, 2008.

ARCHANGELO, E. R. et al. Sorção, dessorção e potencial de lixiviação de atrazine em solos brasileiros. R. Bras. Milho Sorgo, v. 4, n. 1, p. 14-27, 2005.
BRASIL. Ministério da Agricultura, Pecuária e Abastecimento. Sistema de Agrotóxicos Fitossanitários. Brasília: 2005. Disponível em: $<$ http:// extranet.agricultura.gov.br/agrofit_cons/ principal_agrofit_cons>. Acesso em: 14 fev. 2011.

CELIS, R. et al. Sorption and leaching behaviour of polar aromatic acids in agricultural soils by batch and column leaching tests. Europ. J. Soil Sci., v. 56, n. 3, p. 287-297, 2005.

CHOPRA, I. et al. Evaluation of leaching behavior of pendimethalin in sandy loam soil. Environ. Monitor. Assess., v. 160, n.1, p. 123-126, 2010.

COLEMAN, J. O. D. et al. Exploiting plant metabolism for the phytoremediation of persistent herbicides. Environ. Sci. Pol. Res., v. 9, n. 1, p. 18-28, 2002.

DE PAULA, R. T. Mobilidade de atrazine e ametryn em Latossolo Vermelho-Amarelo. 2007. 105 f. Dissertação (Mestrado em Agroquímica) - Universidade Federal de Viçosa, Viçosa, MG, 2007. 
DUBUS, I., et al. Sensitivity analyses for four pesticide leaching models. Pest Management Science. v. 59, p. $962-982,2003$.

\section{EMPRESA BRASILEIRA DE PESQUISA}

AGROPECUÁRIA - EMBRAPA. Centro Nacional de Pesquisa de Solos Manual de métodos de análise de solos. 2.ed. Rio de Janeiro: 1997. 212 p.

FERRI, M. V. W. et al. Atividade dos herbicidas flumetsulam e trifluralin em diferentes valores de $\mathrm{pH}$ e densidade do solo. Ci. Rural, v. 30, n. 1, p. 11-15, 2000

GOULART, S. M. et al. Low-temperature clean-up method for the determination of pyrethroids in milk using gas chromatography with electron capture detection. Talanta, v. 75 , n. 5, p. 1320-1323, 2008.

INOUE, M. H. et al. Potencial de lixiviação de imazapic e isoxaflutole em colunas de solo. Planta Daninha, v. 25, n. 3, p. $547-555,2007$.

JACOMINI, A. E. et al. Determination of ametryn in river water, river sediment and bivalve mussels by liquid chromatography-tandem mass spectrometry. J. Braz. Chem. Soc., v. 20, n. 1, p. 107-116, 2009.

KORDEL, W., KLEIN, M. Prediction of leaching and groundwater contamination by pesticides. Pure and Applied Chemistry, v. 78, n. 5, p. 1081-1090, 2006.
MONQUERO, P. A. et al. Lixiviação de clomazone + ametryn, diuron + hexazinone e isoxaflutole em dois tipos de solo. Planta Daninha, v. 26, n. 3, p. 685-691, 2008.

MONQUERO, P. A. et al. Lixiviação e persistência dos herbicidas sulfentrazone e imazapic. Planta Daninha, v. 28, n. 1, p. 185-195, 2010.

PROCÓPIO, S. O. et al. Influência da matéria orgânica do solo na atividade de herbicidas. B. Inf. SBCS, v. 27, n. 2, p. $13-18,2002$.

QUEIROZ, M. E. C.; LANÇAS, F. M. HRGC study of sorption and dessorption of atrazine, ametryn and Metolachlor on Brazilian soils. J. Braz. Chem. Soc., v. 8, n. 1, p. 1-6, 1997.

ROSSI, C. V. S. et al. Mobilidade do sulfentrazone em Latossolo Vermelho e em chernossolo. Planta Daninha, v. 23 , n. 4 , p. 701-710, 2005

SILVA, A.A.; SILVA, J.F. Ed. Tópicos em manejo de plantas daninhas. Viçosa: Ed. UFV, 2007. 367 p.

VIEIRA, H. P. et al. Otimização e validação da técnica de extração líquido-líquido com partição em baixa temperatura (ELL-PBT) para piretróides em água e análise por CG.

Química Nova, v. 30, n. 3, p. 535-540, 2007. 